\title{
ANALISIS METODE BAYESIAN MENGGUNAKAN NON-INFORMATIF PRIOR UNIFORM DISKRIT PADA SISTEM ANTREAN PELAYANAN GERBANG TOL MUKTIHARJO
}

\author{
Dini Febriani $^{1^{*}}$, Sugito $^{2}$, Alan Prahutama ${ }^{3}$ \\ 1,2,3 Departemen Statistika, Fakultas Sains dan Matematika, Universitas Diponegoro \\ *febrianidini.df@gmail.com
}

\begin{abstract}
The growth rate of the traffic that is high resulting in congestion on the road network system. One of the government's efforts in addressing the issue with the build highways to reduce congestion, especially in large cities. One of the queuing phenomena that often occurs in the city of Semarang is the queue at the Toll Gate Muktiharjo, that the queue of vehicles coming to make toll payment. This study aims to determine how the service system at the Toll Gate Muktiharjo. This can be known by getting a queue system model and a measure of system performance from the distribution of arrival and service. The distribution of arrival and service are determined by finding the posterior distribution using the Bayesian method. The bayesian method combine the likelihood function of the sample and the prior distribution. The likelihood function is a negative binomial. The prior distribution used a uniform discrete. Based on the calculations and analysis, it can be concluded that the queueing system model at the Toll Gate Muktiharjo is a (Beta/Beta/5):(GD/ $/ \infty / \infty)$. The queue simulation obtained that the service system Toll Gate Muktiharjo is optimal based on the size of the system performance because busy probability is higher than jobless probability.
\end{abstract}

Keywords: toll gate muktiharjo, queue, bayesian, beta, size of the system performance

\section{PENDAHULUAN}

Berbagai kota besar di Indonesia berada dalam tahap pertumbuhan urbanisasi yang tinggi akibat laju pertumbuhan ekonomi yang pesat sehingga kebutuhan penduduk untuk melakukan pergerakan menjadi semakin meningkat. Tingkat pertumbuhan lalulintas yang tinggi akan mengakibatkan kemacetan pada sistem jaringan jalan. Kemacetan terjadi ketika pergerakan dilakukan pada daerah yang sama dan waktu yang bersamaan pula. Permasalahan kemacetan biasanya timbul karena kebutuhan transportasi lebih besar daripada prasarana transportasi yang tersedia (Tamin, 2000). Kemacetan dengan volume kendaraan yang besar akan menimbulkan antrean yang terlalu panjang.

Teori antrean dapat diterapkan pada sistem pelayanan di Gerbang Tol Muktiharjo dengan mengetahui model antrean yang tepat dan ukuran kinerja sistem yang dapat digunakan untuk menentukan banyaknya fasilitas pelayanan yang efisien bagi pengguna jalan dan pengusaha. Menurut Risdiyanto (2014), keseimbangan antara jumlah fasilitas pelayanan yang beroperasi dengan tingkat kedatangan kendaraan diperlukan agar pengusaha dan pengguna jalan mendapatkan keuntungan optimum.

Inferensi statistik merupakan metode-metode yang dapat menghasilkan kesimpulan dari keseluruhan data. Metode inferensi yang menggabungkan informasi saat ini dengan informasi sebelumnya yang bersifat subjektif (distribusi prior) yaitu metode Bayes (Walpole \& Myers, 1995). Teorema Bayes merupakan satu-satunya cara yang konsisten dalam mengubah keyakinan tentang parameter setelah mendapatkan informasi sampel dengan 
mendapatkan distribusi posterior (Bolstad, 2017). Data prior yang digunakan dalam penelitian ini yaitu penelitian Sihotang (2019).

\section{TINJAUAN PUSTAKA}

\subsection{Profil Umum Jasa Marga}

PT Jasa Marga (Persero) Tbk merupakan Badan Usaha Milik Negara Indonesia yang didirikan pada tanggal 1 Maret 1978 melalui Peraturan Pemerintah No. 4 Tahun 1978 untuk mendukung gerak pertumbuhan ekonomi Indonesia dengan jaringan jalan yang handal. Tugas utama Jasa Marga adalah merencanakan, membangun, mengoperasikan dan memelihara jalan tol serta sarana dan kelengkapannya agar jalan tol dapat berfungsi sebagai jalan bebas hambatan yang memberikan manfaat lebih tinggi daripada jalan umum bukan tol. Gerbang Tol Transaksi di Jalan Tol Semarang ada empat, yaitu Gerbang Tol Manyaran, Tembalang, Gayamsari dan Muktiharjo. Gerbang Tol Muktiharjo adalah gerbang tol yang memberikan fasilitas Gardu Tol Otomatis untuk kendaraan yang datang dari Pelabuhan Semarang, Demak dan Kudus (Jasa Marga Semarang, 2019).

\subsection{Ukuran Steady-State}

Menurut Taha (1996), $\rho$ didefinisikan sebagai perbandingan antara rata-rata pelanggan yang datang $(\lambda)$ dengan rata-rata pelanggan yang telah dilayani per satuan waktu $(\mu)$, atau dapat dituliskan dengan $\rho=\frac{\lambda}{c \mu}$. $\rho<1$ maka dapat diartikan bahwa kondisi steadystate terpenuhi atau kondisi sifat-sifat suatu sistem tidak berubah dengan berjalannya waktu (konstan).

\subsection{Proses Poisson dan Distribusi Eksponensial}

Menurut Gross dan Harris (1998), umumnya proses antrean diasumsikan bahwa waktu antar kedatangan dan waktu pelayanan mengikuti distribusi Eksponensial atau sama dengan jumlah kedatangan dan jumlah pelayanan mengikuti distribusi Poisson. Untuk suatu proses Poisson, jumlah kedatangan terjadi pada interval waktu t adalah variable acak yang mengikuti distribusi Poisson dengan rata-rata $\lambda t$ dan probabilitas dari $n$ kedatangan adalah $P_{n}(t)=\frac{(\lambda t)^{-n} e^{-\lambda t}}{n !}$. Jika kedatangan mengikuti proses Poisson dengan parameter $\lambda$, maka suatu variable acak berurutan akan mengikuti distribusi Eksponensial dengan parameter $\frac{1}{\lambda}$.

\subsection{Uji Kecocokan Distribusi}

Menurut Daniel (1989), salah satu metode keselarasan yang paling umum digunakan, yaitu uji keselarasan Kolmogorov-Smirnov.

a. Menentukan Hipotesis

$\mathrm{H}_{0}$ : Distribusi sampel mengikuti distribusi yang ditetapkan

$\mathrm{H}_{1}$ : Distribusi sampel tidak mengikuti distribusi yang ditetapkan

b. Menentukan Taraf Signifikansi

Taraf signifikansi yang digunakan adalah $\alpha=5 \%$

c. Statistik Uji

dengan:

$$
D=\operatorname{Sup}_{x}\left|S(x)-F_{0}(x)\right|
$$

$\mathrm{S}(\mathrm{x}) \quad$ : fungsi peluang kumulatif yang dihitung dari data sampel

$\mathrm{F}_{0}(\mathrm{x}) \quad$ : fungsi distribusi yang dihipotesiskan (fungsi peluang kumulatif)

d. Kriteria Uji

Tolak $\mathrm{H}_{0}$ jika pada taraf signifikansi $\alpha$ nilai $\mathrm{D} \geq$ nilai $\mathrm{D}_{\text {tabel }}(1-\alpha)$ atau jika nilai sig. $<$ nilai $\alpha$. $\mathrm{D}_{\text {tabel }}(\alpha)$ adalah nilai kritis yang diperoleh dari tabel Kolmogorov-Smirnov. 


\subsection{Model-Model Sistem Antrean}

\subsubsection{Model (M/M/c): $(\mathrm{GD} / \infty / \infty)$}

Menurut Taha (1996), model ini menunjukkan bahwa pelanggan tiba dengan laju konstan, maksimum $c$ pelanggan dapat dilayani secara bersamaan, dan laju pelayanan per pelayanan adalah konstan. Rumus untuk mencari ukuran-ukuran kinerja pada model antrean $(\mathrm{M} / \mathrm{M} / \mathrm{c}):(\mathrm{GD} / \infty / \infty)$ adalah sebagai berikut:

$$
\begin{aligned}
& \text { dengan } P_{0}=\left\{\sum_{n=0}^{c-1} \frac{\rho^{n}}{n !}+\frac{\rho^{c}}{c !\left(1-\frac{\rho}{c}\right)}\right\}^{-1}, \frac{\rho}{c}<1 \\
& L q=\left[\frac{\rho^{c+1}}{(c-1) !(c-\rho)^{2}}\right] P_{0} \\
& L s=L q+\rho \\
& W q=\frac{L q}{\lambda} \\
& W s=W q+\frac{1}{\mu}
\end{aligned}
$$

\subsubsection{Model (G/G/c): $(\mathrm{GD} / \infty / \infty)$}

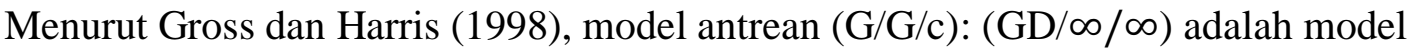
antrean dengan pola kedatangan dan pola pelayanan berdistribusi umum (general) dengan jumlah fasilitas pelayanan sebanyak $c$, disiplin antrean FIFO (First In First Out), kapasitas maksimum, dan memiliki sumber pemanggilan tak hingga. Rumus untuk mencari ukuran-

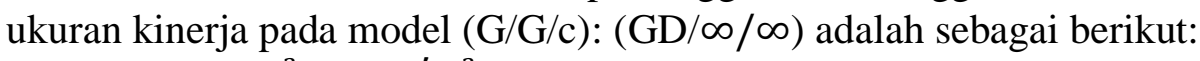

$L q=L_{q M / M / c} \frac{\mu^{2} v(t)+v\left(t^{\prime}\right) \lambda^{2}}{2}$

dengan:

$v(t)$ adalah $\left(\frac{1}{\mu^{2}}\right)^{2}$

$v\left(t^{\prime}\right)$ adalah $\left(\frac{1}{\lambda^{2}}\right)^{2}$

$L s=L q+\rho$

$W q=\frac{L q}{\lambda}$

$W s=W q+\frac{1}{\mu}$

\subsection{Distribusi Binomial Negatif}

Menurut Walpole \& Myers (1995), Peubah acak diskrit Y berdistribusi binomial negatif dengan parameter $k$ dan $p$ yang fungsi kepadatan peluangnya:

$f(y)=\left\{\begin{array}{c}\left(\begin{array}{c}y-1 \\ k-1\end{array}\right) p^{k}(1-p)^{y-k}, y=k, k+1, k+2, \ldots \\ 0, \text { lainnya }\end{array}\right.$

\subsection{Distribusi Uniform Diskrit}

Menurut Bain and Engelhardt (1992), sebuah variable random diskrit Y berdistribusi uniform diskrit untuk 1,2, .., $\mathrm{k}$ jika memiliki fungsi kepadatan peluang sebagai berikut:

$f(y)=\frac{1}{N}, \mathrm{y}=1,2, \ldots, \mathrm{N}$ 


\subsection{Distribusi Beta}

Menurut Walpole \& Myers (1995), Peubah acak kontinu Y berdistribusi beta dengan parameter $\alpha>0$ dan $\beta>0$ apabila fungsi kepadatan peluangnya berbentuk

$$
f(y)=\left\{\begin{aligned}
\frac{\Gamma(\alpha+\beta)}{\Gamma(\alpha) \Gamma(\beta)} y^{\alpha-1}(1-y)^{\beta-1}, & 0<y<1 \\
0, & \text { lainnya }
\end{aligned}\right.
$$

\subsection{Metode Bayesian}

Dalam pendekatan bayesian $\lambda$ dipandang sebagai besaran yang variasinya digambarkan dengan distribusi prior dimana distribusi tersebut didasarkan pada keyakinan seseorang dan dirumuskan sebelum data diambil. Kemudian sampel diambil dari populasi dan distribusi prior disesuaikan dengan informasi sampel yang diperoleh. Prior yang disesuaikan tersebut akan membentuk distribusi posterior (Subanar, 2019).

\subsection{Metode Jeffreys}

Menurut Box dan Tiao (1973), bentuk pendekatan dalam menentukan prior noninformatif yang pertama kali dikenalkan oleh Sir Harold Jeffreys yaitu metode Jeffreys. Metode ini menyatakan bahwa distribusi prior non-informatif untuk parameter $\lambda$ proporsional dengan akar kuadrat dari informasi Fisher yang dinyatakan dalam:

$p(\lambda)=[I(\lambda)]^{1 / 2}$

$I(\lambda)=E\left[\frac{\partial \log L(\lambda)}{\partial \lambda}\right]^{2}$

\subsection{Fungsi Likelihood}

Menurut Bain dan Engelhardt (1992), fungsi likelihood adalah fungsi dari parameter $\lambda$ dan dinotasikan dengan $L(\lambda)$. Jika $Y_{1}, Y_{2}, \ldots, Y_{n}$ menyatakan suatu sampel random dari $f(y \mid \lambda)$, maka:

$$
\begin{aligned}
L(\lambda) & =f\left(y_{1} \mid \lambda\right) f\left(y_{2} \mid \lambda\right) \ldots f\left(y_{n} \mid \lambda\right) \\
& =\prod_{i=1}^{n} f\left(y_{i} \mid \lambda\right)
\end{aligned}
$$

\subsection{Distribusi Posterior}

Menurut Bain dan Engelhardt (1992), distribusi posterior dinyatakan dalam bentuk

$f(\lambda \mid y)=\frac{f\left(y_{1}, y_{2}, \ldots, y_{n} \mid \lambda\right) p(\lambda)}{\int f\left(y_{1}, y_{2}, \ldots, y_{n} \mid \lambda\right) p(\lambda) d(\lambda)}$

dimana $f\left(y_{1}, y_{2}, \ldots, y_{n} \mid \lambda\right)$ merupakan fungsi likelihood dan $p(\lambda)$ merupakan distribusi priornya.

\section{METODE PENELITIAN}

\subsection{Sumber Data dan Variabel Penelitian}

Data yang digunakan pada penelitian ini adalah data primer dari hasil pengamatan secara langsung yang dilaksanakan selama 7 hari dengan bantuan software Xnote Stopwatch 1.60 dan data prior penelitian sebelumnya yaitu penelitian Sihotang (2019). Variabel penelitian yang digunakan adalah:

a. Data jumlah kedaraan yang datang dan dilayani di Gerbang Tol Muktiharjo.

b. Data jumlah kendaraan yang datang dan dilayani di Gerbang Tol Muktiharjo pada penelitian sebelumnya sebagai data prior. 


\subsection{Langkah-langkah Analisis}

Analisis data menggunakan bantuan software Easy Fit dan GUI R. Adapun langkahlangkah analisis dalam penelitian ini sebagai berikut:

1. Melakukan penelitian secara langsung di Gerbang Tol Muktiharjo untuk mendapatkan data jumlah kendaraan yang datang dan data jumlah kendaraan yang dilayani.

2. Melakukan pengujian kondisi steady-state $\left(\rho=\frac{\lambda}{c \mu}<1\right)$ pada data yang telah diperoleh, dengan $\lambda$ sebagai rata-rata kedatangan kendaraan dan $\mu$ sebagai rata-rata kendaraan yang telah dilayani.

3. Melakukan uji kecocokan distribusi poisson untuk jumlah kedatangan kendaraan dan kendaraan yang dilayani dengan menggunakan uji Kolmogorov Smirnov. Jika hipotesis untuk distribusi jumlah kedatangan kendaraan dan jumlah kendaraan dilayani diterima maka distribusinya mengikuti distribusi poisson. Apabila hipotesisnya ditolak maka dicari distribusi lainnya yang sesuai dengan menggunakan software Easy Fit.

4. Melakukan uji Kolmogorov Smirnov untuk uji kecocokan distribusi lainnya yang sesuai.

5. Menentukan likelihood dari distribusi data sampel yang telah diperoleh.

6. Menghitung distribusi posterior dengan menggunakan distribusi priornya yaitu pada penelitian Sihotang (2019).

7. Menentukan model antrean yang sesuai dengan distribusi posteriornya.

8. Membangkitkan data sesuai dengan parameter distribusi posterior yang telah diperoleh.

9. Menghitung ukuran kinerja sistem berdasarkan data posterior, yaitu jumlah pelanggan yang diperkirakan dalam sistem $\left(L_{s}\right)$, jumlah pelanggan yang diperkirakan dalam antrean $\left(L_{q}\right)$, waktu menunggu yang diperkirakan dalam sistem $\left(W_{S}\right)$, dan waktu menunggu yang diperkirakan dalam antrean $\left(W_{q}\right)$.

10. Membuat simulasi sistem antrean dengan banyaknya gardu sebanyak 3, 4, 5 dan 6 .

11. Mengambil kesimpulan mengenai pelayanan kendaraan di Gerbang Tol Muktiharjo.

\section{HASIL DAN PEMBAHASAN}

\subsection{Deskripsi Data Sampel}

Data sampel yang digunakan dalam penelitian ini yaitu data jumlah kedatangan dan jumlah pelayanan kendaraan yang dihitung mulai dari pukul 07.00 WIB sampai dengan 17.00 WIB pada setiap lajurnya. Waktu pelayanan kendaraan dihitung sejak kendaraan sejajar dengan mesin GTO dan waktu selesai dilayani dihitung saat palang pintu tol terbuka.

Tabel 1. Tabel Jumlah Kendaraan yang Datang dan Dilayani Setiap Hari

\begin{tabular}{ccc}
\hline Hari & $\begin{array}{c}\text { Jumlah Kendaraan yang } \\
\text { Datang }\end{array}$ & $\begin{array}{c}\text { Jumlah Kendaraan yang } \\
\text { Dilayani }\end{array}$ \\
\hline Kamis & 5883 & 5877 \\
Jumat & 7516 & 7511 \\
Sabtu & 7867 & 7864 \\
Minggu & 6483 & 6479 \\
Senin & 7068 & 7060 \\
Selasa & 7252 & 7247 \\
Rabu & 7377 & 7374 \\
\hline Total & 49446 & 49412 \\
\hline
\end{tabular}


Berdasarkan Tabel 1, dapat dilihat bahwa jumlah kendaraan yang datang untuk melakukan pembayaran di Gerbang Tol Muktiharjo mulai pukul 07.00 WIB sampai dengan pukul 17.00 WIB dalam 7 hari yaitu 49446 kendaraan. Sedangkan jumlah kendaraan yang dilayani mulai pukul 07.00 WIB sampai dengan pukul 17.00 WIB dalam 7 hari yaitu 49412 kendaraan. Jumlah kendaraan yang datang dan dilayani paling banyak terjadi pada hari Sabtu.

\subsection{Ukuran Steady State Data Sampel}

Berikut adalah tabel hasil perhitungan ukuran steady state berdasarkan data sampel:

Tabel 2. Ukuran Steady State Data Sampel

\begin{tabular}{cccc}
\hline$c$ & $\lambda$ & $\mu$ & $\rho=\frac{\lambda}{c \mu}$ \\
\hline 5 & 353,1857 & 352,9429 & 0,2001 \\
\hline
\end{tabular}

Nilai $\rho<1$ menunjukkan kondisi steady-state pada sistem antrean pelayanan kendaraan di Gerbang Tol Muktiharjo terpenuhi.

\subsection{Uji Kecocokan Distribusi Data Sampel}

Uji kecocokan distribusi pada data jumlah kedatangan kendaraan dan jumlah kendaraan yang dilayani bertujuan untuk mengetahui apakah data jumlah kendaraan yang datang dan jumlah kendaraan yang dilayani berdistribusi poisson atau distribusi lainnya.

Tabel 3. Uji Kolmogorov-Smirnov

\begin{tabular}{ccccc}
\hline $\begin{array}{c}\text { Jumlah } \\
\text { Kendaraan }\end{array}$ & $\mathbf{D}_{\text {hitung }}$ & $\mathbf{D}_{\text {tabel }}$ & Keputusan & Kesimpulan \\
\hline Kedatangan & 0,3432 & 0,1149 & $\mathrm{H}_{0}$ ditolak & $\begin{array}{c}\text { Data tidak berdistribusi } \\
\text { Poisson }\end{array}$ \\
Pelayanan & 0,3430 & 0,1149 & $\mathrm{H}_{0}$ ditolak & $\begin{array}{c}\text { Data tidak berdistribusi } \\
\text { Poisson }\end{array}$ \\
\hline
\end{tabular}

Berdasarkan Tabel 3, data jumlah kendaraan yang datang dan dilayani tidak memenuhi distribusi poisson sehingga perlu dilakukan uji kecocokan distribusi berdasarkan output software Easy Fit.

Tabel 4. Uji Kolmogorov-Smirnov Distribusi General

\begin{tabular}{ccccc}
\hline $\begin{array}{c}\text { Jumlah } \\
\text { Kendaraan }\end{array}$ & $\mathbf{D}_{\text {hitung }}$ & $\mathbf{D}_{\text {tabel }}$ & Keputusan & Kesimpulan \\
\hline Kedatangan & 0,0447 & 0,1149 & $\mathrm{H}_{0}$ diterima & $\begin{array}{c}\text { Data berdistribusi } \\
\text { Binomial Negatif } \\
\text { Data berdistribusi } \\
\text { Binomial Negatif }\end{array}$ \\
\hline
\end{tabular}

\subsection{Fungsi Likelihood}

Data jumlah kendaraan yang datang dan dilayani berdistribusi binomial negatif, diperoleh fungsi likelihood

$$
\begin{aligned}
L(\lambda) & =\prod_{i=1}^{n} f\left(y_{i}\right) \\
& =\prod_{i=1}^{n}\left(\begin{array}{c}
y_{i}-1 \\
k-1
\end{array}\right) \lambda^{k}(1-\lambda)^{y_{i}-k}
\end{aligned}
$$




\subsection{Prior}

$$
=\lambda^{n k}(1-\lambda)^{\sum_{i=1}^{n} y_{i}-n k} \prod_{i=1}^{n}\left(\begin{array}{c}
y_{i}-1 \\
k-1
\end{array}\right)
$$

Distribusi Prior berdasarkan data penelitian Sihotang (2019) untuk data jumlah kendaraan yang datang dan dilayani yaitu berdistribusi uniform diskrit. Berikut nilai noninformatif prior

$$
\begin{aligned}
& f(y ; \lambda)=\frac{1}{\lambda} \\
& L(\lambda)=\lambda^{-n} \\
& \frac{\partial \log L}{\partial \lambda}=\frac{-n}{\lambda} \\
& I(\lambda)=E\left(\frac{\partial \log L}{\partial \lambda}\right)^{2} \\
& =E\left(\frac{-n}{\lambda}\right)^{2} \\
& =\frac{n^{2}}{\lambda^{2}} \\
& f(\lambda)=\sqrt{I(\lambda)} \\
& =\frac{n}{\lambda}
\end{aligned}
$$

\subsection{Distribusi Posterior}

Setelah didapatkan fungsi likelihood dari data sampel dan non-informatif prior maka diperoleh distribusi posterior dari data jumlah kendaraan yang datang dan dilayani adalah sebagai berikut:

$$
\begin{aligned}
f(\lambda \mid y) & =\frac{f\left(y_{1}, y_{2}, \ldots, y_{n} \mid \lambda\right) p(\lambda)}{\int_{0}^{1} f\left(y_{1}, y_{2}, \ldots, y_{n} \mid \lambda\right) p(\lambda) d(\lambda)} \\
& =\frac{\lambda^{n k}(1-\lambda)^{\sum_{i=1}^{n} y_{i}-n k} n \lambda^{-1} \prod_{i=1}^{n}\left(\begin{array}{c}
y-1 \\
k-1
\end{array}\right)}{\int_{0}^{1} \lambda^{n k}(1-\lambda)^{\sum_{i=1}^{n} y_{i}-n k} n \lambda^{-1} \prod_{i=1}^{n}\left(\begin{array}{l}
y-1 \\
k-1
\end{array}\right) d(\lambda)} \\
& =\frac{\lambda^{n k}(1-\lambda)^{\sum_{i=1}^{n} y_{i}-n k} n \lambda^{-1} \prod_{i=1}^{n}\left(\begin{array}{l}
y-1 \\
k-1
\end{array}\right)}{n \prod_{i=1}^{n}\left(\begin{array}{l}
y-1 \\
k-1
\end{array}\right) \int_{0}^{1} \lambda^{n k}(1-\lambda)^{\sum_{i=1}^{n} y_{i}-n k} \lambda^{-1} d(\lambda)} \\
& =\frac{\lambda^{n k-1}(1-\lambda)^{\sum_{i=1}^{n} y_{i}-n k}}{\int_{0}^{1} \lambda^{n k-1}(1-\lambda)^{\sum_{i=1}^{n} y_{i}-n k} d(\lambda)} \\
& =\frac{\Gamma\left(\sum_{i=1}^{n} y_{i}+1\right)}{\Gamma(n k) \Gamma\left(\sum_{i=1}^{n} y_{i}-n k+1\right)} \lambda^{n k-1}(1-\lambda)^{\sum_{i=1}^{n} y_{i}-n k}
\end{aligned}
$$

Berdasarkan perhitungan di atas maka diperoleh distribusi untuk data jumlah kendaraan yang datang dan dilayani $\sim \operatorname{Beta}\left(n k, \sum_{i=1}^{n} y_{i}-n k+1\right)$.

\subsection{Model Sistem Antrean}

Berdasarkan distribusi posterior yang diperoleh, model sistem antrean untuk data jumlah kendaraan yang datang dan jumlah kendaraan yang dilayani di Gerbang Tol

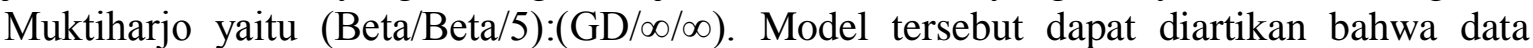
jumlah kendaraan yang datang berdistribusi beta dan data jumlah kendaraan yang dilayani berdistribusi beta dengan banyaknya fasilitas pelayanan yaitu 5 gardu, disiplin antrean yang 
digunakan adalah FIFO (First In First Out) dimana kendaraan yang datang pertama kali akan dilayani terlebih dahulu, serta kapasitas kendaraan dan sumber pemanggilan tidak terbatas.

\subsection{Ukuran Kinerja Sistem Data Posterior}

Ukuran-ukuran kinerja sistem antrean kendaraan di Gerbang Tol Muktiharjo berdasarkan data posterior diperoleh jumlah pelanggan dalam antrean, jumlah pelanggan dalam sistem, waktu yang diperkirakan dalam antrean, waktu yang diperkirakan dalam sistem dan probabilitas sistem antrean tidak sibuk.

Tabel 6. Ukuran Kinerja Sistem Antrean Kendaraan Gerbang Tol Muktiharjo

\begin{tabular}{cccccc}
\hline$c$ & $L_{q}$ & $L_{s}$ & $W_{q}$ & $W_{s}$ & $P_{0}$ \\
\hline 5 & $5,35174 \times 10^{-9}$ & 1,000758 & $1,26218 \times 10^{-11}$ & 0,002359643 & 0,3675 \\
\hline
\end{tabular}

\subsection{Simulasi Sistem Antrean}

Simulasi dilakukan untuk mengetahui gambaran mengenai pelayanan kendaraan di Gerbang Tol Muktiharjo apabila terdapat 3 gardu, 4 gardu, 5 gardu, dan 6 gardu dengan mengetahui ukuran-ukuran kinerja sistem.

Tabel 7. Simulasi Sistem Antrean Kendaraan di Gerbang Tol Muktiharjo

\begin{tabular}{ccccc}
$\begin{array}{c}\text { Ukuran Kinerja } \\
\text { Sistem }\end{array}$ & $\mathrm{c}=3$ & $\mathrm{c}=4$ & $\mathrm{c}=5$ & $\mathrm{c}=6$ \\
\hline$L_{q}$ & $2,53655 \times 10^{-7}$ & $3,79822 \times 10^{-8}$ & $5,35147 \times 10^{-9}$ & $6,85562 \times 10^{-10}$ \\
$L_{S}$ & 1,000758643 & 1,000758427 & 1,000758395 & 1,00075839 \\
$W_{q}$ & $5,98081 \times 10^{-10}$ & $8,95566 \times 10^{-11}$ & $1,2618 \times 10^{-11}$ & $1,61646 \times 10^{-12}$ \\
$W_{S}$ & 0,00235964372 & 0,00235964321 & 0,00235964313 & 0,00235964312 \\
$P_{0}$ & 0,363348151 & 0,367066556 & 0,367536982 & 0,367593552 \\
\hline
\end{tabular}

\section{KESIMPULAN}

Berdasarkan hasil dan pembahasan pada penelitian di Gerbang Tol Muktiharjo, dapat disimpulkan bahwa distribusi posterior untuk data jumlah kendaraan yang datang dan jumlah kendaraan yang dilayani yaitu Beta dengan parameter $n k$ dan $\sum_{i=1}^{n} y_{i}-n k+1$. Model

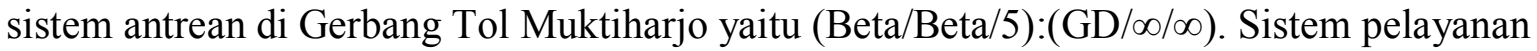
kendaraan di Gerbang Tol Muktiharjo dapat dikatakan sudah baik berdasarkan nilai-nilai ukuran kinerja sistem yang didapatkan. Nilai $\mathrm{P}_{0}$ yang diperoleh ketika banyaknya gardu yang disediakan 5 gardu yaitu 0,3675 atau 36,75\%. Artinya, tingkat kesibukan sistem antrean lebih besar daripada sistem antrean tidak sibuk. Kemudian, berdasarkan simulasi antrean dengan gardu yang disediakan sebanyak 5 memiliki tingkat kesibukan yang hampir sama dengan kondisi ketika gardu yang disediakan 6. Waktu kendaraan menunggu untuk dilayani lebih lama apabila hanya disediakan 4 gardu. Maka dapat dikatakan pelayanan sudah optimal dengan kondisi gardu yang disediakan sebanyak 5 gardu. Namun, pada masa pandemi apabila instansi ingin mengurangi operating cost yang dikeluarkan sebaiknya menutup sementara satu lajur pada jam yang cenderung tidak ramai. 


\section{DAFTAR PUSTAKA}

Bain, L. J. dan Engelhardt, M. 1992. Introduction Probability and Mathematical Statistics Second Edition. California: Duxburry Press.

Bolstad, W. M. 2017. Introduction To Bayesian Statistics Third Edition. America: John Wiley \& Sons, Inc.

Box, G. E. P. dan Tiao, G. C. 1973. Bayesian Inference In Statistical Analysis. Philippines: Addision-Wesley Publishing Company.

Daniel, W. W. 1989. Statistik Nonparametrik Terapan. Diterjemahkan oleh: Alex Tri Kantjono W. Jakarta: PT. Gramedia. Terjemahan dari: Applied Nonparametric Statistics.

Gross, D. dan Harris, C. 1998. Fundamental of Queueing Theory: Third Edition. New York: John Willey and Sons, Inc.

Jasa Marga. 2019. Sekilas Jasa Marga. https://www.jasamarga.com/public/id/infoperusahaan/ProfilPerusahaan/Overview.as px. Diakses: 17 Maret 2021

Kakiay, T. J. 2004. Dasar Teori Antrian untuk Kehidupan Nyata. Yogyakarta: Andi.

Risdiyanto. 2014. Rekayasa \& Manajemen Lalu Lintas Teori dan Aplikasi. Yogyakarta: LeutikaPrio.

Subagyo, P. Asri, M. dan Handoko, T. H. 1992. Dasar-Dasar Operation Research. Yogyakarta: BPFE.

Subanar. 2019. Inferensi Bayesian dengan R. Yogyakarta: UGM Press.

Taha, H. A. 1996. Riset Operasi, Jilid Dua. Jakarta: Binarupa Aksara.

Tamin, O. Z. 2000. Perencanaan dan Pemodelan Transportasi, Edisi Kedua. ITB.

Walpole, R. E. 1995. Ilmu Peluang dan Statistika untuk Insinyur dan Ilmuwan, Edisi Keempat. Diterjemahkan oleh: RK Sembiring. Bandung: ITB. Terjemahan dari: Probability and Statistics for Engineers and Scientists.

Wrediningsih A. P., Sugito, Prahutama A., and Hakim A. R. 2018. Non-Poisson queueing model's identification (Case study: AKAP and AKDP bus on the West Lines bus service of Tirtonadi Surakarta). Journal of Physics. IOP Publishing. 